\title{
Wood-based Boards Mechanical Properties and Their Effects on the Cutting Process during Shredding
}

\begin{abstract}
M. Kukla,* and Ł. Warguła
In order to design effective shredding machines dedicated to shredding wood-based waste, information about the mechanical properties of materials subjected to shredding is necessary. A number of mechanical properties of particleboard, oriented strand boards, and medium-density fibreboards in the aspect of shredding process have been experimentally determined in the article. The influence of material type, blade geometries, and cutting depth on cutting force and elasticity coefficient were analysed. Blade geometries reflect different phases of rotation of the cylindrical wood chipper's knife. It has been shown that a knife with the most favourable geometry is characterized by the lowest values of the stiffness coefficient for each of the materials. This is the geometry of the cylindrical wood chipper's knife exactly halfway into the cutting process. By contrast, the least favourable geometry is characterized by a knife corresponding to the beginning of the cutting process. Among the tested materials, the medium density board requires the most energy to change its structure, and the laminated particleboard requires the least. The presented results can be a set of input data necessary to model the work required to implement the cutting process, but also enable validation of existing cutting models.
\end{abstract}

Keywords: Particleboard; Oriented standard boards; Medium-density fibreboards; Knife geometry; Wood chipper; Wood-based materials

Contact information: Department of Mechanical Engineering, Institute of Machine Design, Poznan University of technology, Piotrowo 3 St., 735 BM, 61-139 Poznań, Poland;

*Corresponding author: mateusz.kukla@ put.poznan.pl

\section{INTRODUCTION}

Wood-based materials and their composites are used in an increasing number of industries. First of all, they have been used in the furniture (Mirski et al. 2017), packaging (Nassef et al. 2018; Palka and Tutak 2018), and construction industries (Heidari et al. 2019), in which they constitute the low-emission construction sector (Hildebrandt et al. 2017). Wood-based materials consist mainly of wood chips and dust covered with, for example, PVC laminates (Narlığlu et al. 2018), laminated with thermally compressed veneer (Buyuksari 2012), décor paper, and resin/impregnated décor papers (Istek et al. 2010) or coated with veneers and continuous press laminates (Nemli and Çolakoğlu 2005). The most commonly used furniture materials are plywood and particleboard, the latter of which includes oriented strand boards (OSB), as well as low-density (LDF), mediumdensity (MDF), or high-density fibreboards (HDF) (Wasielewski 2019). Such materials mainly consist of wood fibres and contain up to $10 \%$ synthetic additives, such as adhesives (Mirski et al. 2020), laminates, varnishes and surface modifiers (Stubdrup et al. 2016; Wasielewski 2019). Due to the improvement of a number of their properties, one can notice the intensive development of materials from this group towards protective coatings as well as additions in the composition (base material core (Kramár et al. 2020)) or subsequent

Kukla \& Warguła (2021). "Shredding of wood boards," BioResources 16(4), 8006-8021. 8006 
composite coatings. Examples of ways to improve properties in terms of the methods used include, but are not limited to, reinforcement by adding reinforced fibre polymers (Kramár et al. 2020) or polyvinyl acetate (PVAC) (Kramár et al. 2020). Increasing water and mould resistance could be achieved through application of superhydrophobic treatment recipes (Wang et al. 2020). Increasing fire resistance has been obtained by using, e.g., composite coatings of inorganic nanomaterials with polyelectrolytes (Zhou and $\mathrm{Fu} 2020$ ), fire retardants (Bachtiar et al. 2019), or increasing resistance using carbon-based materials (Seo et al. 2016). Increasing the resistance to adverse effects of climatic conditions by, for example, impregnating nanocomposites (Lin et al. 2020). There is also a tendency to improve the aesthetic value by using laminates, paints, or impregnants (Kržišnik et al. 2018). This is also intended to reduce prices, provide easier service, better biodegradability, or the possibility to reuse in the recycling process (Carvalho Araújo et al. 2019). In addition, the composition of wood-based materials is enriched due to the situation related to the problems of wood scarcity and forest protection. Thanks to it, techniques for implementing winter rape (Gajdačová et al. 2018) or food packaging waste (Nassef et al. 2018) for the production of wood-based materials are being developed.

Such a diverse and complex matter as the modern wood-based board is considered to be problematic waste and requires appropriate disposal. However, it should be taken into account that this waste is characterized by a high content of wood, which is a biodegradable component. This may bring additional benefits related to the qualification and settlement of produced energy as such, which comes, to some extent, from renewable sources (Wasielewski and Bałazińska 2017). The chemical energy contained in such waste can be used for energy purposes, such as the production of electricity or heat in various technological variants of thermochemical processing, e.g. combustion, pyrolysis, gasification, plasma processes, and their combinations (EC-DGE 2003; Król 2008; Reczulski 2015; Wasielewski and Bałazińska 2017). Combustion of this type of waste is carried out in specially adapted installations, limiting the emission of harmful substances into the atmosphere, of which dust, volatile ashes, acid gases, as well as heavy metal aerosols cause the greatest concern (Król 2008). Appropriate selection of combustion parameters and the use of appropriate flue gas cleaning technology can provide a lowemission heat source (Król 2008). Modern furnaces used in such processes are adapted for combustion of the shredded waste. In addition, shredding waste facilitates its transport (Reczulski 2015) and storage (Warguła et al. 2020a), but also supports the technological processes of combustion (Macko and Mroziński 2018, 2019; Warguła et al. 2019). Woodbased materials, despite the prevailing biomaterial content, pose an ecological threat at various stages of the product's life cycle. However, as a waste they can be employed as a biofuel (Walkowiak et al. 2018), which can be regarded as a low-emission heat source (Król 2008) if in the technological process stringent legislative requirements are met (Wasielewski and Bałazińska 2017). Effective shredding processes are necessary for such management of these materials.

The goal of designing effective shredding machines and modelling processes associated with them is to know the mechanical properties of the shredded materials. The availability of a great variety of wood-based materials, additionally expanded by additives that change their properties, means that a large number of tests of their physical and mechanical properties have been carried out (Pritchard et al. 2001; Ayrilmis et al. 2007; Ganev et al. 2007; Akyüz et al. 2010; de Barros Filho et al. 2011; Rydzkowski and Michalska-Pożoga 2016; Akyildiz et al. 2018). Among them one can distinguish, research in the basic strength of materials field (bending, twisting, compression, tension, surface 
pressure) and dynamic tests (Nassef et al. 2018). Researchers also have considered: determination of the modulus of elasticity (Cetera et al. 2018; Bakhta et al. 2020), internal bond characteristics (Cetera et al. 2018), impact of water (swelling) (Cetera et al. 2018; Bakhta et al. 2020), moisture absorption (Trochonowicz and Galas 2018), impact of thermal treatment (Cetera et al. 2018), impact of type of removal machining on processed materials (Martínez-Conde et al. 2017), formaldehyde emission during drying (Cetera et al. 2018), and acoustic emission during machining (Eschelbacher et al. 2019). However, there has been a lack of material properties description affecting the cutting force during shredding of wood-based waste. Available models for estimating the force when cutting or machining wood or wood-based materials are available for machines such as: circular saw (Porankiewicz et al. 2011; Orłowski et al. 2013; Kopecký et al. 2014), band saw (Orlowski and Ochrymiuk 2017; Chuchała and Orłowski 2018), chain saw (Kuvik et al. 2017), largesize crusher (Yu et al. 2012), and milling machine (Džinčić and Skakić 2012; Guo et al. 2015; Mandić et al. 2015; Krauss et al. 2016; Durković et al. 2018; Kopecký et al. 2019; Wei et al. 2018). However, there is no information for designers of machines shredding furniture waste regarding the value of forces that their cutting mechanisms must carry. This also translates into the power requirements of their drive systems. The right choice of drive unit, without too much power reserve, translates into measurable ecological and economic benefits related to energy saving of the implemented process (Waluś et al. 2018; Szpica et al. 2018; Szpica and Czaban 2019; Warguła et al. 2020b). That is why it is so important to conduct research in this area. The general goal of the research work was to determine a number of physical quantities, to prepare a set of guidelines, and to develop mathematical models that will support the process of designing energy-efficient machines for chipping wood and wood-based materials. The aim of this paper, as part of the indicated research works, was to determine the mutual relations between the stiffness coefficient of commonly used wood-based materials and the variable geometry of the blade resulting from the shredding process using a rotary tool.

\section{EXPERIMENTAL}

\section{Materials}

During the tests, four types of commonly used furniture boards were used, namely: particleboard with laminate $(\mathrm{PBL})$, particleboard without laminate $(\mathrm{PB})$, oriented strand boards (OSB), as well as medium-density fibreboards (MDF) with thickness of $18 \mathrm{~mm}$. Boards were supplied by a manufacturer Swiss Krono and can be considered typical, commercially available material. Samples of approximately $180 \times 90 \mathrm{~mm}$ in size were cut from the boards, which were then seasoned to obtain a uniform moisture content of $7 \%$. Detailed characteristics of the materials together with the mechanical properties declared by the manufacturer are presented in Table 1 .

\section{Methods}

The tests were performed using the MTS Insight testing machine, which allowed for the simultaneous measurement of force and displacement. The test consisted of mounting the knife into machine's grip mounted rigidly on the traverse, followed by pressing it into the centres of samples at a certain velocity (traverse speed) and to a specific depth (strain amplitude). 
Table 1. Characteristics of the Tested Materials Properties

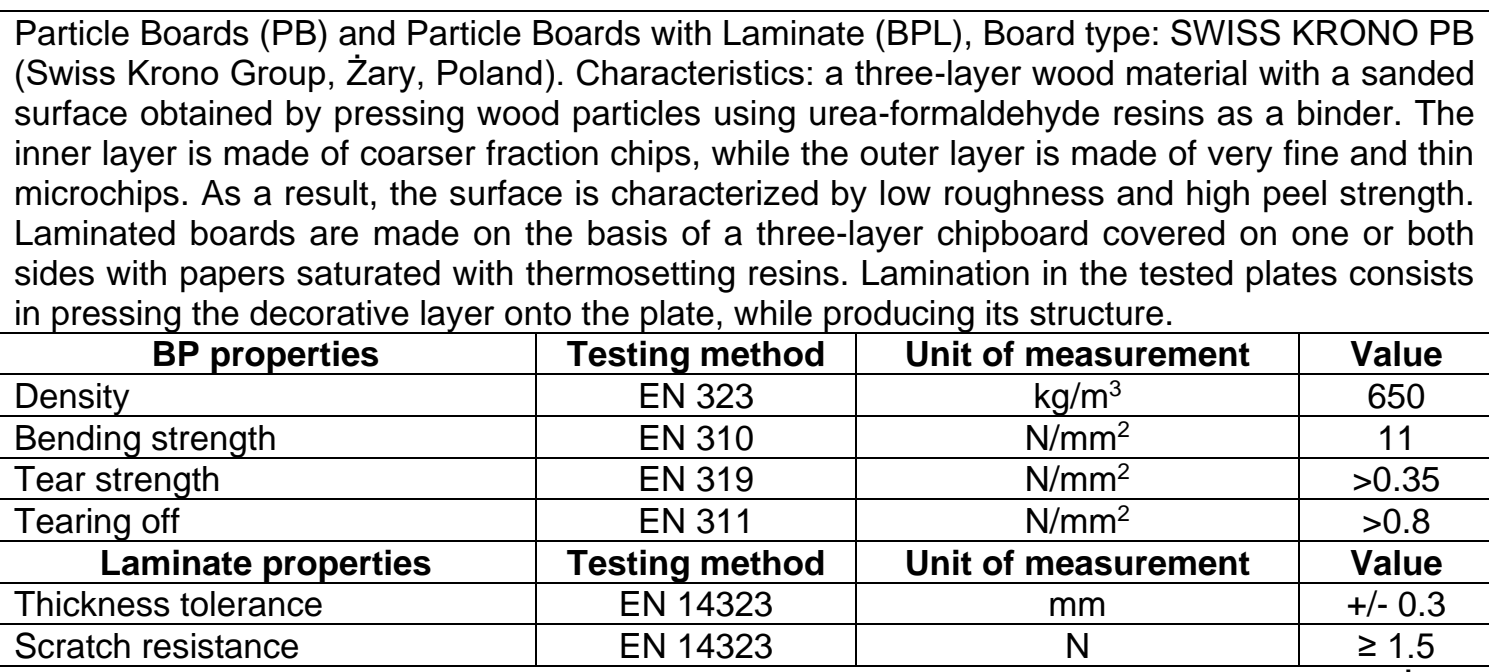

Oriented strand board (OSB), Board type: SWISS KRONO OSB/2 (Swiss Krono Group, Żary,

Poland). Characteristics: load bearing plate for use in dry conditions with directed structure. It is a wood product, a flat-pressed three-layer board, which consists of rectangular flat chips, which under the influence of high pressure and temperature, using synthetic resins as a binder, are pressed by hot rolling.

\begin{tabular}{|l|c|c|c|}
\hline \multicolumn{1}{|c|}{ Properties } & Testing method & Unit of measurement & Value \\
\hline Density & EN 323 & $\mathrm{kg} / \mathrm{m}^{3}$ & 625 \\
\hline Bending strength: major axis & EN 310 & $\mathrm{N} / \mathrm{mm}^{2}$ & 18 \\
\hline Bending strength: lateral axis & EN 310 & $\mathrm{N} / \mathrm{mm}^{2}$ & 9 \\
\hline Modulus of elasticity: major axis & EN 310 & $\mathrm{N} / \mathrm{mm}^{2}$ & 3500 \\
\hline Modulus of elasticity: lateral axis & EN 310 & $\mathrm{N} / \mathrm{mm}^{2}$ & 1400 \\
\hline $\begin{array}{l}\text { Tensile strength perpendicular } \\
\text { to the board plane }\end{array}$ & EN 319 & $\mathrm{N} / \mathrm{mm}^{2}$ & 0.30 \\
\hline Thickness swelling after 24h & EN 317 & $\%$ & 20 \\
\hline Surface soundness & EN 311 & $\mathrm{N} / \mathrm{mm}^{2}$ & $>0.6$ \\
\hline
\end{tabular}

Medium-density fibreboard (MDF), Board type: SWISS KRONO MDF EPF-S (Swiss Krono Group, Żary, Poland). Characteristics: wood-based material formed by pressing wood fibres with the addition of organic binding and hardening compounds under high pressure and temperature conditions. It is characterized by a homogeneous density and raw material composition throughout the entire cross-section.

\begin{tabular}{|l|c|c|c|}
\hline \multicolumn{1}{|c|}{ Properties } & Testing method & Unit of measurement & Value \\
\hline Density & EN 323 & $\mathrm{kg} / \mathrm{m}^{3}$ & 750 \\
\hline Bending strength & EN 310 & $\mathrm{N} / \mathrm{mm}^{2}$ & 20 \\
\hline Integral bond & EN 319 & $\mathrm{N} / \mathrm{mm}^{2}$ & 0.55 \\
\hline Models of elasticity & EN 310 & $\mathrm{N} / \mathrm{mm}^{2}$ & 2200 \\
\hline Swelling after 24h & EN 317 & $\%$ & 12 \\
\hline Tearing off & EN 311 & $\mathrm{N} / \mathrm{mm}^{2}$ & $>1$ \\
\hline
\end{tabular}

The tests on OSB were always carried out in such a way that the blade was placed perpendicular to the fibres of the board, which in case of others board's types had little significance due to more uniform internal structure. During such an experiment, changes in the value of force and displacement over time were recorded in a laboratory room with the following conditions: temperature of $22^{\circ} \mathrm{C}$ and air humidity of $7 \%$. The speed of the machine's traverse was $v=0.1 \mathrm{~mm} / \mathrm{s}$. The assumed values of the strain amplitude were: $\varepsilon_{1}$ $=0.13, \varepsilon_{2}=0.26, \varepsilon_{3}=0.39, \varepsilon_{4}=0.52$, and $\varepsilon_{5}=0.65 \mathrm{~mm} / \mathrm{mm}$. Five knives were used in the experiment $\left(k_{1}-k_{5}\right)$ with different geometry, which were made of HADOX steel, type 
500. The geometry of the blades reproduces the cutting tool of the cylindrical wood chipper in various phases of rotation when cutting the material (Fig. 1a and 1b). As can be observed from Fig. 1, the decreasing numbering of the knives from $k_{5}$ to $k_{1}$ corresponds to the increasing angles of the rotary cutting tool, which corresponds to the earlier contact of the blade and the material. Three repetitions were performed for a every single knife $\left(n_{1}-n_{3}\right)$ for the same strain amplitude. As a result of accepting such a number of experiment variants, 300 measurement tests were performed. The presented markings have been consistently preserved throughout the paper.

Based on the recorded data, the characteristics of force dependence on displacement were determined for each of the measurement tests. On this basis, the stiffness coefficients defined as the directional linear regression coefficients from the measured data were determined. This regression was calculated from the beginning of the coordinate system to the maximum value of force registered in the experiment. The arithmetic mean was used as the searched value estimator $\bar{x}$ from three values of the stiffness coefficient $k$ set for subsequent repetitions (from $n_{1}$ to $n_{3}$ ). The standard deviation of the arithmetic mean was assumed as the error of the searched value $\sigma$.

The values determined in this way were compared for analysis. Statistical analysis was performed at the significance level set as $\alpha=0.05$. The Anderson-Darling test was used to determine the distribution normality of measured data. Then, two-parameter analysis of variance (ANOVA) was used to determine the strain amplitude impact and knife geometry on the dependent variable for which the mean value of the stiffness coefficient $k$ was assumed. A Tukey's post hoc test was applied when a significant difference was detected in the between-subject factor.

In order to assess the differentiation of individual stiffness coefficients, the variation coefficient values $(C V)$ were determined. This gave base to the analysis of how the discussed values differ for particular strain amplitudes and different materials.

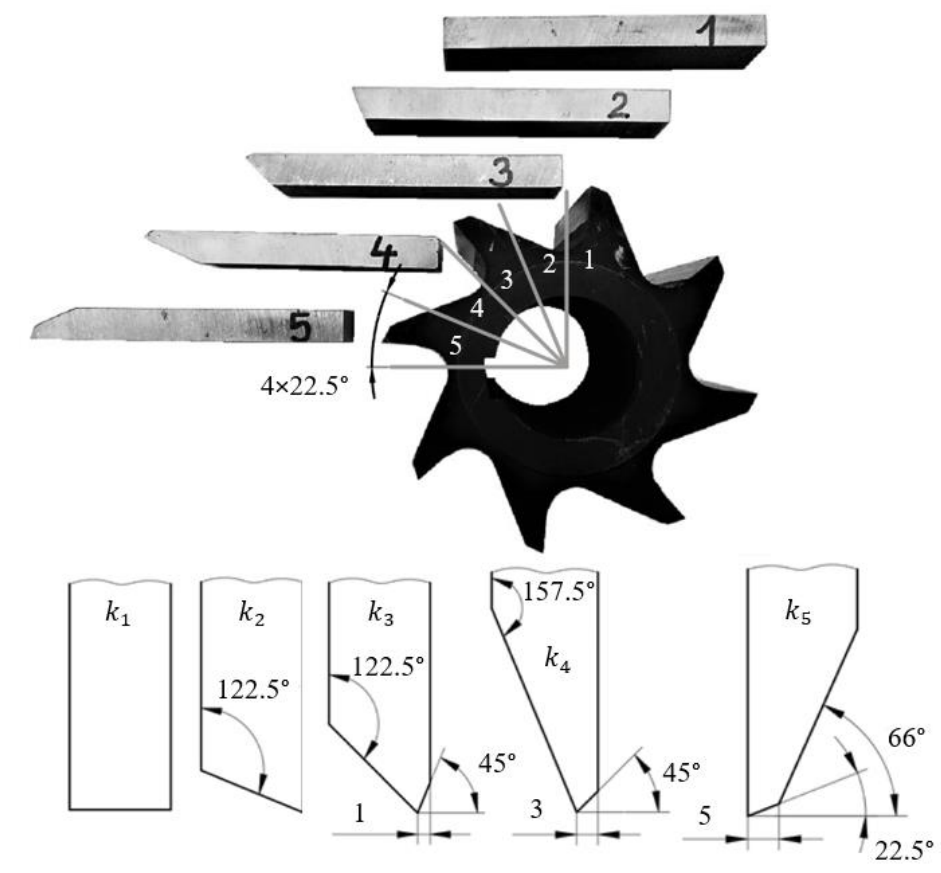

Fig. 1. Geometry of knives used in the study 


\section{RESULTS AND DISCUSSION}

The calculated arithmetic means together with standard deviations for all experiment variants are presented in Table 2 . The statistical data of the analysis of variance (ANOVA) has been presented in Table 3. The selected set of registered data is shown in Fig. 2 (MDF, $k_{1}$ ).

Table 2. Calculated Values of the Stiffness Coefficient (From Three Repetitions $\left.n_{1}-n_{3}\right)$

\begin{tabular}{|c|c|c|c|c|c|c|c|c|c|c|}
\hline & \multicolumn{2}{|c|}{$k_{1}$} & \multicolumn{2}{|c|}{$k_{2}$} & \multicolumn{2}{|c|}{$k_{3}$} & \multicolumn{2}{|c|}{$k_{4}$} & \multicolumn{2}{|c|}{$k_{5}$} \\
\hline MDF & $\bar{x}$ & $\sigma$ & $\overline{\bar{x}}$ & $\sigma$ & $\overline{\bar{x}}$ & $\sigma$ & $\overline{\bar{x}}$ & $\sigma$ & $\overline{\bar{x}}$ & $\sigma$ \\
\hline$\varepsilon_{1}$ & 2571 & 114.4 & 976 & 132.1 & 973 & 56.2 & 1007 & 35.2 & 983 & 12.0 \\
\hline$\varepsilon_{2}$ & 2232 & 50.6 & 1133 & 24.6 & 816 & 33.9 & 797 & 8.3 & 1072 & 41.2 \\
\hline$\varepsilon_{3}$ & 2097 & 74.0 & 1228 & 32.3 & 757 & 24.6 & 740 & 12.1 & 984 & 109.4 \\
\hline$\varepsilon_{4}$ & 2089 & 55.4 & 1361 & 46.3 & 788 & 14.5 & 671 & 15.5 & 953 & 10.0 \\
\hline$\varepsilon_{5}$ & 2139 & 74.1 & 1471 & 57.5 & 852 & 38.8 & 613 & 11.2 & 898 & 32.8 \\
\hline PBL & $\bar{x}$ & $\sigma$ & $\bar{x}$ & $\sigma$ & $\bar{x}$ & $\sigma$ & $\bar{x}$ & $\sigma$ & $\bar{x}$ & $\sigma$ \\
\hline$\varepsilon_{1}$ & 1415 & 30.5 & 671 & 43.0 & 688 & 27.3 & 686 & 53.5 & 805 & 139.1 \\
\hline$\varepsilon_{2}$ & 1189 & 25.2 & 660 & 48.3 & 530 & 5.4 & 535 & 46.0 & 650 & 27.3 \\
\hline$\varepsilon_{3}$ & 1341 & 13.0 & 692 & 56.0 & 541 & 57.1 & 509 & 27.2 & 655 & 11.6 \\
\hline$\varepsilon_{4}$ & 1574 & 99.1 & 927 & 54.2 & 557 & 38.9 & 499 & 37.9 & 756 & 9.9 \\
\hline$\varepsilon_{5}$ & 1601 & 310.1 & 1180 & 28.7 & 648 & 50.6 & 534 & 32.8 & 735 & 47.1 \\
\hline PB & $\bar{x}$ & $\sigma$ & $\bar{x}$ & $\sigma$ & $\overline{\boldsymbol{x}}$ & $\sigma$ & $\overline{\boldsymbol{x}}$ & $\sigma$ & $\overline{\boldsymbol{x}}$ & $\sigma$ \\
\hline$\varepsilon_{1}$ & 1800 & 80.4 & 862 & 58.4 & 875 & 6.2 & 745 & 68.2 & 852 & 5.6 \\
\hline$\varepsilon_{2}$ & 1491 & 91.2 & 805 & 38.4 & 704 & 36.5 & 591 & 32.4 & 749 & 7.1 \\
\hline$\varepsilon_{3}$ & 1503 & 57.4 & 874 & 38.4 & 635 & 29.1 & 616 & 45.4 & 813 & 26.7 \\
\hline$\varepsilon_{4}$ & 1635 & 25.8 & 1029 & 41.0 & 726 & 13.3 & 571 & 17.9 & 836 & 58.8 \\
\hline$\varepsilon_{5}$ & 1818 & 7.4 & 1270 & 100.1 & 726 & 22.8 & 642 & 52.2 & 867 & 73.4 \\
\hline OSB & $\bar{x}$ & $\sigma$ & $\overline{\bar{x}}$ & $\sigma$ & $\overline{\bar{x}}$ & $\sigma$ & $\bar{x}$ & $\sigma$ & $\bar{x}$ & $\sigma$ \\
\hline$\varepsilon_{1}$ & 1006 & 249.0 & 1110 & 77.0 & 755 & 31.3 & 708 & 106.5 & 1281 & 142.8 \\
\hline$\varepsilon_{2}$ & 1200 & 103.7 & 944 & 144.0 & 693 & 42.2 & 665 & 42.3 & 1173 & 139.3 \\
\hline$\varepsilon_{3}$ & 1195 & 35.4 & 920 & 114.5 & 679 & 124.5 & 583 & 61.0 & 893 & 273.8 \\
\hline$\varepsilon_{4}$ & 1383 & 119.6 & 1099 & 155.6 & 662 & 71.9 & 554 & 43.2 & 834 & 219.0 \\
\hline$\varepsilon_{5}$ & 1551 & 209.5 & 1266 & 145.9 & 744 & 208.8 & 552 & 50.6 & 789 & 49.2 \\
\hline \multicolumn{11}{|c|}{$\varepsilon_{1}-\varepsilon_{5}-$ amplitude values $(\mathrm{mm} / \mathrm{mm})$} \\
\hline \multicolumn{11}{|c|}{$\bar{x}-$ arithmetic mean $(\mathrm{N} / \mathrm{mm})$} \\
\hline \multicolumn{11}{|c|}{$\sigma-$ standard deviation $(\mathrm{N} / \mathrm{mm})$} \\
\hline$l$ & & knives & & & & & & & & \\
\hline
\end{tabular}

Table 3. Statistical Data of the Analysis of Variance (ANOVA); F - F Test Value, $p$-value - Test Probability of ANOVA Analysis; $\alpha=0.05$

\begin{tabular}{|l|c|c|c|c|c|c|c|c|}
\cline { 2 - 10 } \multicolumn{1}{c|}{} & \multicolumn{2}{c|}{ MDF } & \multicolumn{2}{c|}{ PBL } & \multicolumn{2}{c|}{ PB } & \multicolumn{2}{c|}{ OSB } \\
\cline { 2 - 10 } \multicolumn{1}{c|}{} & $F$ & $p$-value & $F$ & $p$-value & $F$ & $p$-value & $F$ & $p$-value \\
\hline Knife & 1716.73 & $7.73 \mathrm{E}-53$ & 296.08 & $3.86 \mathrm{E}-34$ & 1016.12 & $3.36 \mathrm{E}-47$ & 57.21 & $4.71 \mathrm{E}-18$ \\
\hline Strain & 15.09 & $3.73 \mathrm{E}-08$ & 20.18 & $6.04 \mathrm{E}-10$ & 45.23 & $5.02 \mathrm{E}-16$ & 2.12 & 0.09 \\
\hline Interaction & 23.24 & $1.02 \mathrm{E}-17$ & 6.32 & $2.27 \mathrm{E}-07$ & 11.81 & $7.26 \mathrm{E}-12$ & 4.15 & $5.55 \mathrm{E}-05$ \\
\hline
\end{tabular}


Figure 3 shows how the value of the coefficient of variation for individual materials and strain amplitudes changes with the division into knives of different geometry. Figure 4 shows how the stiffness coefficients changes depending on the type of knife for different amplitude values during the process conducted on MDF. Figure 5 shows how the stiffness coefficient changes depending on the type of material for different amplitude values during the process conducted with knife $k_{3}$.

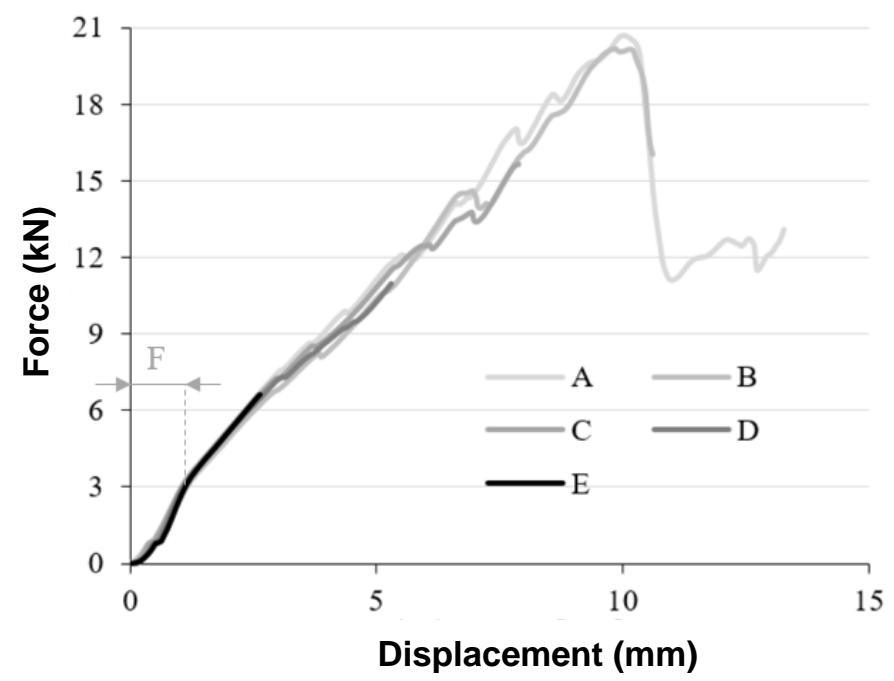

Fig. 2. Selected set of registered data for MDF and knife $k_{1}$; individual markings: $A-\varepsilon_{1}, \mathrm{~B}-\varepsilon_{2}, \mathrm{C}$ $-\varepsilon_{3}, \mathrm{D}-\varepsilon_{4}, \mathrm{E}-\varepsilon_{5}, \mathrm{~F}-$ initial part of the force-displacement diagram with different inclination angle - detailed description in discussion section

As the results of calculations suggest, the recorded data (Fig. 2) can be approximated with a very high accuracy by means of a linear function in the range from zero to the maximum force value. The vast majority of the coefficient of determination $\mathrm{R}^{2}$ was greater than 0.9. A smaller value of this coefficient was recorded for only 36 of 300 cases. The smallest value determined is $\mathrm{R}^{2}=0.8138$. Thus, data regression using linear function can be considered as very good in the vast majority.

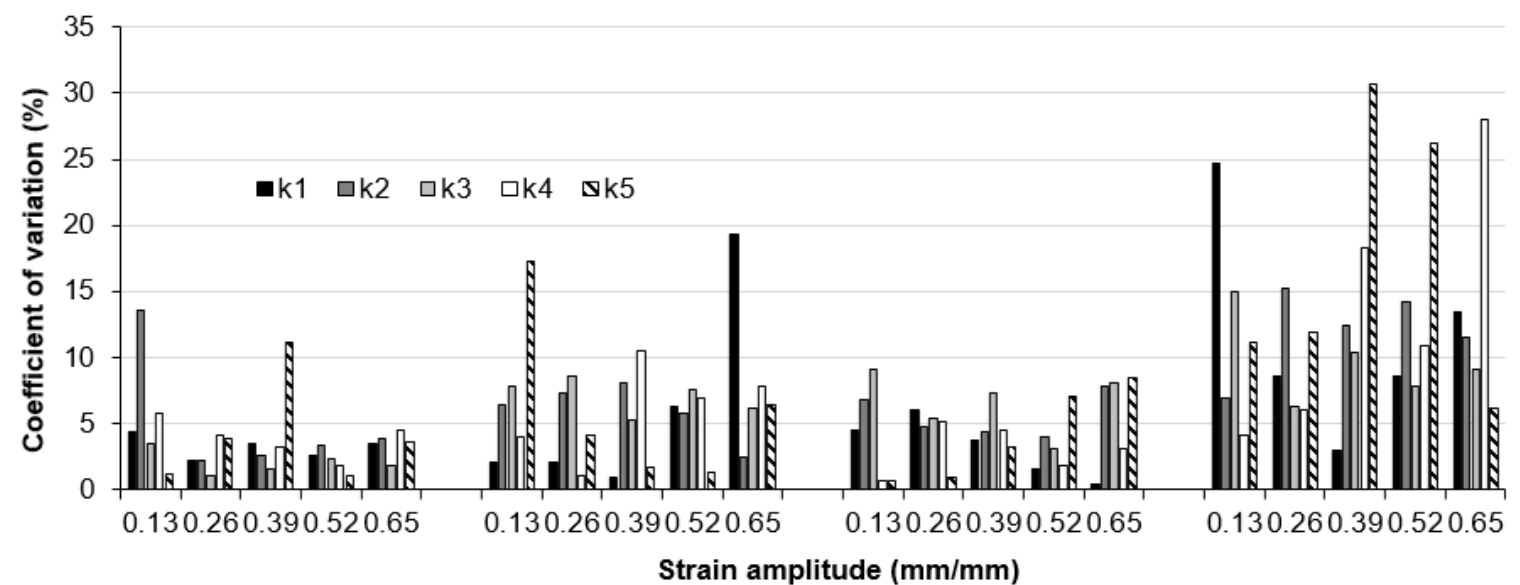

Fig. 3. The coefficient of variation value for individual materials and strain amplitudes divided into knives with different geometry 


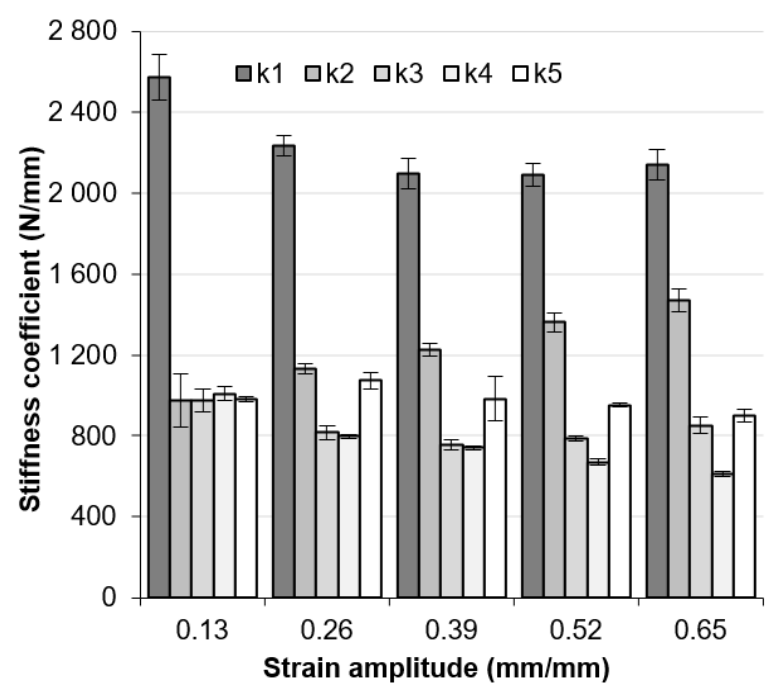

Fig. 4. Change of the stiffness coefficient depending on the type of knife for different amplitude values (material: MDF)

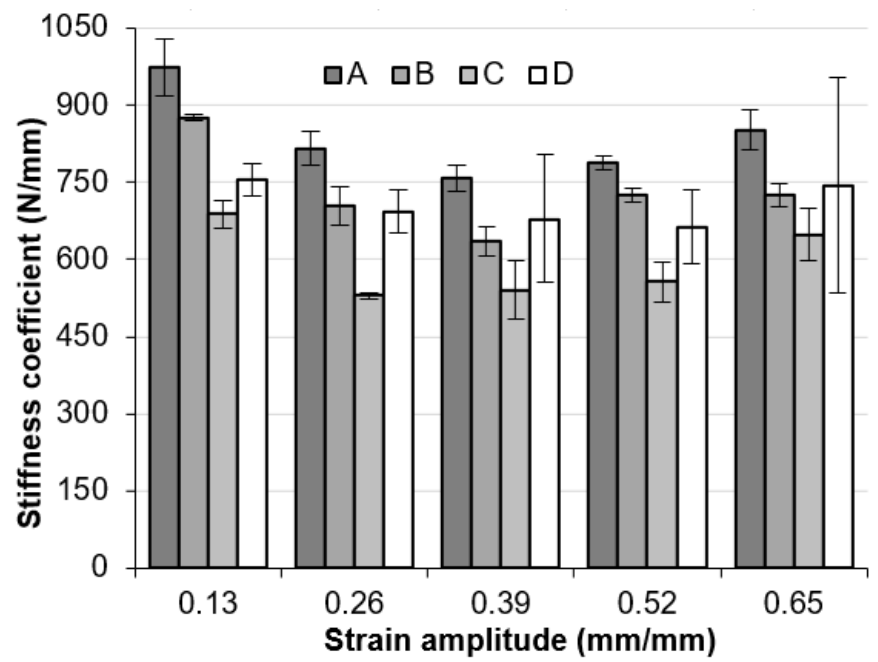

Fig. 5. Change of stiffness coefficient depending on the type of material for different amplitude values (knife: $k_{3}$ ); individual markings $\mathrm{A}-\mathrm{MDF}, \mathrm{B}-\mathrm{PB}, \mathrm{C}-\mathrm{PBL}, \mathrm{D}-\mathrm{OSB}$

Analysis of variance showed that for each type of material there were statistically significant differences in the average values of the stiffness coefficient between knives with different geometries $(p<0.05)$. This is attributed to the different shape of the cutting edges, which affects the recorded load values (Wojtkowiak et al. 2018). As a result, the force with which the knife acts on the material is divided into its components, which causes a complex state of stress. As a result, the stresses reduced in cross-section tangent to the cutting edge of the punch consist of compressive, bending, and shear stresses. Changing the angle of the blade causes a change in the force necessary to cut the material. This is very well illustrated by comparing the values of the stiffness coefficients in Fig. 2. Using a flat knife $\left(k_{1}\right)$ results in a larger scale of strength value increase, i.e. the determined stiffness coefficient. The measured values for this case deviate significantly from the others. The knife with the most favourable geometry is definitely the knife $k_{4}$, since its use resulted in the lowest stiffness coefficient values for each of the materials. Interestingly, the post hoc 
test showed that for cases: MDF knives $k_{3}$ and $k_{4}$ as well as OSB knives $k_{2}$ and $k_{5}$ but also knives $k_{3}$ and $k_{4}$ there were no statistically significant differences in arithmetic means.

Blade geometries reflect different rotational phases of the cylindrical wood chipper's knife. The results indicate (Fig. 4) that the knife $k_{4}$ has the most favourable geometry due to the increase in the cutting force. This is the geometry of the cylindrical wood chipper's knife when the process is midway. This means that it is only after half of the cutting process that the blade obtains the most effective cutting parameters. The shape of the tool is also important because it also affects the quality of the cut surfaces (Wojtkowiak and Talaśka 2019). Whereas the knife $k_{1}$ is characterized by the least favourable geometry, its shape corresponds to the mutual arrangement of the knife edge and material during the cutting process initial phase. This is a very unfavourable phenomenon, because it additionally increases the analysed process impact character, which causes a dynamic load on the working and drive elements of the wood chipper.

Analysis of variance showed that for OSB there were no statistically significant differences between the average values of the stiffness coefficient depending on the progressing strain $(F=2.12, p=0.092)$. Analysis of the data contained in Table 2 and the graph presented in Fig. 2 make it possible to conclude that the determined coefficient values $k$ change significantly. However, the statistical analysis carried out support a statement, with high probability, that these changes are not the effect of the strain amplitude influence. The results for OSB achieve the highest values, this is the result of their highest resistance among tested materials (Rebollar et al. 2007). Most likely, this is due to the internal structure of the material. All tested materials consist of shredded wood-based materials; however the slender OSB chips have the largest geometric dimensions. In the smaller chips case, the process of destroying the material structure is more dependent on the binder strength, which is usually various types of resins and glues. In OSB, while cutting, the knife edge must cut more chips. This may be the reason for the faster force value increase during the process, which is observed by higher values of the stiffness coefficient.

The results of the ANOVA for MDF indicate statistically significant differences in the determined stiffness coefficient $k$ values. However, the post hoc test showed that the source of this variation was the values recorded for $\varepsilon_{1}$ amplitude (the smallest value). Comparison results for all other amplitudes against each other $\left(\varepsilon_{2}-\varepsilon_{5}\right)$ showed no significant differences. Perhaps such an observation can be explained by the internal structure of the material, and more precisely - its density. In the first stage of cutting (for a low strain value), material crushing causing its compaction may dominate. Only after reaching a certain strain value does the share of actual cutting in the registered force value becomes more significant. This interpretation is supported by the initial part of the force diagram presented in Fig. 2 - and marked as dimension " $F$ ". Its analysis shows a different inclination angle of the force-displacement curve for small strain values. This nature of results was observed for each knife type used in the experiment.

The results recorded for PBL and PB (Fig. 5) are generally characterized by significant statistical differences in the values of the stiffness coefficient $k$. Exceptions that can be made based on the post hoc test for a WL board are: $\varepsilon_{1}$ and $\varepsilon_{4}$. $\varepsilon_{2}$ and $\varepsilon_{3}$ and $\varepsilon_{4}$ and $\varepsilon_{5}$. However, for the PB they were: $\varepsilon_{1}$ and $\varepsilon_{5}$ and $\varepsilon_{2}$ and $\varepsilon_{3}$. The highest stiffness coefficient values were recorded for MDF in cutting with knives $k_{1}-k_{4}$ and for a knife $k_{5}$ the highest values occurred during the use of OSB. In all experiment cases, it was determined that the PB had a higher stiffness coefficient than the PBL. Perhaps this is due to the fact that the 
PB was characterized by increased density at external surfaces to improve its aesthetic properties, which may translate into the stiffness coefficient value. In contrast, the laminated board structure is the same throughout the cross-section, and the outer layer is filled with laminate, improving its aesthetic value.

Coefficient of variation analysis (Fig. 3) shows that the results for MDF were characterized by the least variability. On the other hand, the greatest differentiation was found in the stiffness coefficient values for OSB. Again, this nature of the recorded results can be related to the internal structure of the material. The chips that OSB consists of are mostly oriented in a specific direction, but they are characterized by various sizes. Other materials consist of smaller chips, but with much more similar dimensions (within a particular type of board). As a result, the recorded results differ from each other. The top layer of OSB has overall similar properties, but the surface area of the used knives is smaller than some strand pieces. Perhaps the observed results diversity comes from conducting the cutting process in different places of individual strand pieces. Overall, the results should be considered as having low variability, since the coefficient of variation was below $25 \%$. The exception to this rule were knives $k_{4}$ (for amplitudes $\varepsilon_{3}=0.39$ and $\varepsilon_{4}=0.52 \mathrm{~mm} / \mathrm{mm}$ ) and $k_{5}$ (for amplitude $\varepsilon_{5}=0.65 \mathrm{~mm} / \mathrm{mm}$ ) for OSB. In those three cases the designated value $C V$ was above $25 \%$.

Registered and presented research results make it possible to state that the process of shredding wood-based boards can be basically divided into two parts. In the first of them, the material is compacted (crumple), and only then it's cut (the proper part of the process). The course of this phenomenon is shown in Fig. 6. Thanks to such observation, it becomes possible to use the available theoretical models of cutting plant origin materials describing this phenomenon, such as the one given by the formula (1),

$$
F_{p}=g \sigma+\frac{E}{2} \cdot \frac{h^{2}}{H}\left[\tan \beta+\mu \sin ^{2} \beta+\mu^{\prime}\left(\mu+\cos ^{2} \beta\right)\right],
$$

where, $F_{p}$ is pressure force per blade length unit, $g$ is the thickness of the blade, $\sigma$ material stresses occurring in cutting, $E$ is the Young's modulus of the material being cut, $h$ is the thickness of the material layer crushed with a knife, $H$ is the total height of the material, $\beta$ is the angle of application of the knife blade, $\mu$ is the material's internal friction angle, and $\mu^{\prime}$ is the friction coefficient between the knife blade and the cut material (Kanafojski and Karwowski 1976).

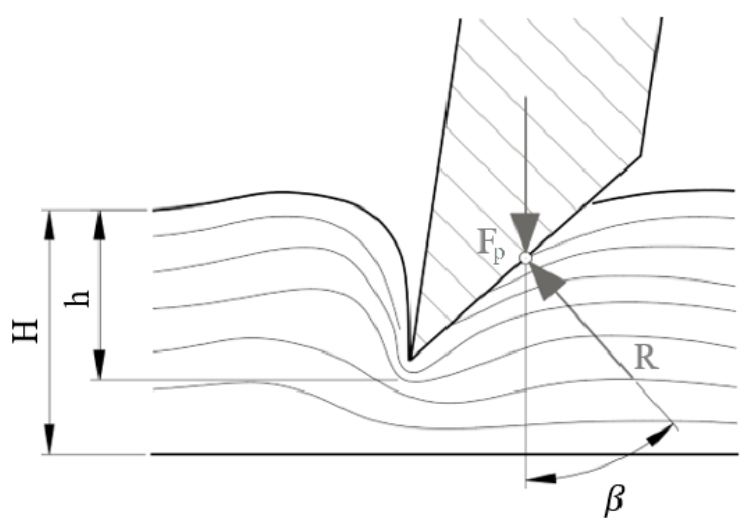

Fig. 6. The force acting on the knife edge at the beginning of cutting plant origin material process; $H$ - the thickness of the material being cut, $h$-thickness of the crushed layer, $R$ - reaction force of the cut material; based on (Kanafojski and Karwowski 1976) 
In the presented model (1), only the first component represents the useful force that is necessary to complete the cutting process. Due to the large variety of plant materials, its value can only be determined based on experiments. Registered test results will serve, among others, to define this physical value. It depends not only on the mechanical properties of the material being cut, but also on how sharp the cutting edge is. The second term of equation (1) is associated with the cutting resistance directly related to the process itself: material crush, internal friction, and friction between the blade and the material being cut. Determining the value of these physical values will be the subject of future research.

\section{CONCLUSIONS}

1. The results of the conducted experiments allowed determination of the stiffness coefficients of the tested materials depending on the strain amplitude, the material type, and the cutting blade geometry. The blade geometry has a significant impact on registered force values in the test. This is particularly important in cylindrical chippers. The angle at which the blade enters the shredded material depends on its thickness because the cutting edge is in rotational motion. For this reason, cutting forces (and therefore the demand for drive torque) can vary considerably with the material thickness, not only because of its larger amount necessary to be cut, but also because of the change in the cutting process geometry itself. This is an important issue that must be considered in the design process of a shredding machine.

2. The type of material has an obvious effect on recorded results. This is a relatively wellrecognized issue. The determined values set can be used as a necessary input data set to model the work required to perform the cutting process. It also adds value to the current state of knowledge because it allows cutting process existing models validation.

3. The strain amplitude significantly affects the stiffness coefficients value $k$ for particleboard with and without laminate, as well as MDF. The calculations results suggest statistically significant differences, but they do not give grounds to determine their nature. Therefore, further research in this area is necessary.

4. There was no significant strain amplitude effect on the recorded values of cutting force increase for OSB.

\section{ACKNOWLEDGMENTS}

Research was performed as part of the project "Interdisciplinary Dean's Grant (IDG) of Poznan University of Technology" determined in the subject for the year 2020 air quality in Poznań and how to improve it. Project title: "Design and research of mobile machines chipping wastes from urban agriculture processes for innovative construction solutions limiting the impact on the natural environment and machine operators" (33/32/SIGR/3334), financed by the Poznan University of Technology.

Kukla \& Warguła (2021). "Shredding of wood boards," BioResources 16(4), 8006-8021. 8016 


\section{REFERENCES CITED}

Akyildiz, M. H., Dogan, K., and Kaymakci, A. (2018). "The impact of density and mixture ratio of melamine on some properties of oriented strand board," Maderas. Ciencia y tecnología 20(3), 417-430.

Akyüz, K. C., Nemli, G., Baharoğlu, M., and Zekoviç, E. (2010). "Effects of acidity of the particles and amount of hardener on the physical and mechanical properties of particleboard composite bonded with urea formaldehyde," Int. J. of Adh. and Adhesives 30(3), 166-169.

Ayrilmis, N., Candan, Z., and White, R. (2007). "Physical, mechanical, and fire properties of oriented strandboard with fire retardant treated veneers," Holz als Rohund Werkstoff 65(6), 449-458.

Bachtiar, E. V., Kurkowiak, K., Yan, L., Kasal, B., and Kolb, T. (2019). “Thermal stability, fire performance, and mechanical properties of natural fibre fabricreinforced polymer composites with different fire retardants," Polymers 11(4), 699.

Büyüksarı, Ü. (2012). "Physical and mechanical properties of particleboard laminated with thermally compressed veneer," BioResources 7(1), 1084-1091.

de Barros Filho, R. M., Mendes, L. M., Novack, K. M., Aprelini, L. O., and Botaro, V. R. (2011). "Hybrid chipboard panels based on sugarcane bagasse, urea formaldehyde and melamine formaldehyde resin," Ind. Crops and Prod. 33(2), 369-373.

Carvalho Araújo, C. K., Salvador, R., Piekarski, C. M., Sokulski, C., de Francisco, A., and de Carvalho Araújo, S. K. (2019). "Circular economy practices on wood panels: a bibliographic analysis,” Sustainability 11(4), 1057.

Cetera, P., Negro, F., Cremonini, C., Todaro, L., and Zanuttini, R. (2018). "Physicomechanical properties of thermally treated poplar OSB," Forests 9(6), 345.

Chuchała, D., and Orłowski, K. (2018). "Forecasting values of cutting power for the sawing process of impregnated pine wood on band sawing machine," Mechanik 2018(8-9), 766-768. [in Polish]

Durković, M., Mladenović, G., Tanović, L., and Danon, G. (2018). “Impact of feed rate, milling depth and tool rake angle in peripheral milling of oak wood on the cutting force," Maderas. Ciencia y Tecnología 20(1), 25-34.

Džinčić, I., and Skakić, D. (2012). "Determing the parameters of wood machinability as a function of tangential cutting force during the process of machining wood by routing," Wood Res. 57(1), 161-172.

EC-DGE (2003). "Refuse derived fuel, current practice and perspectives," Final Raport. European Commission - Directorate General Environment. https://cordis.europa.eu/article/id/15383-refusederived-fuel-current-practice-andperspectives/en?format=pdf Accessed 7 April 2021.

EN 323 (1993). "Wood-based panels - Determination of density, British Standards Institution," European Committee for Standardization, Brussels, Belgium.

EN 310 (1993). "Wood-based panels - Determination of modulus of elasticity in bending and of bending strength," European Committee for Standardization, Brussels, Belgium.

EN 319 (1993). "Particleboards and fibreboards - Determination of tensile strength perpendicular to the plane of the board," European Committee for Standardization, Brussels, Belgium.

EN 311(2004). "Wood-based panels - Surface soundness - Test method," Slovenian Institute for Standardization, Ljubljana, Slovenia. 
EN 317(1993). "Particleboards and fibreboards. Determination of swelling in thickness after immersion in water," Slovenian Institute for Standardization, Ljubljana, Slovenia.

EN 14323(2017). "Wood-based panels - Melamine faced boards for interior uses - Test methods," Slovenian Institute for Standardization, Ljubljana, Slovenia.

Eschelbacher, S., Duntschew, J., and Möhring, H. C. (2019). "Recognition of wood and wood-based materials during machining using acoustic emission," in: Production at the Leading Edge of Technology, pp. 317-325, Springer Vieweg, Berlin, Heidelberg, 2019.

Gajdačová, P., Hýsek, Š., and Jarský, V. (2018). "Utilisation of winter rapeseed in woodbased materials as a solution of wood shortage and forest protection," BioResources 13(2), 2546-2561.

Ganev, S., Gendron, G., Cloutier, A., and Beauregard, R. (2007). "Mechanical properties of MDF as a function of density and moisture content," Wood and Fiber Sci. 37(2), 314-326.

Guo, X., Li, R., Cao, P., Ekevad, M., Cristovao, L., Marklund, B., and Grönlund, A. (2015). "Effect of average chip thickness and cutting speed on cutting forces and surface roughness during peripheral up milling of wood flour/polyvinyl chloride composite," Wood Res. 60, 147-156.

Heidari, M. D., Mathis, D., Blanchet, P., and Amor, B. (2019). "Streamlined life cycle assessment of an innovative bio-based material in construction: A case study of a phase change material panel," Forests 10(2) 160.

Hildebrandt, J., Hagemann, N., and Thrän, D. (2017). “The contribution of wood-based construction materials for leveraging a low carbon building sector in Europe," Sus. Cities and Soc. 34, 405-418.

Istek, A., Aydemir, D., and Aksu, S. (2010). "The effect of décor paper and resin type on the physical, mechanical, and surface quality properties of particleboards coated with impregnated décor papers," BioResources 5(2), 1074-1083.

Kanafojski, C., and Karwowski, T., (1976). "Crop-harvesting machines, in agricultural machines, theory and constructon," Vol. II, Published for the U.S. Department of Agriculture and the National Science Foundation, Washington, D.C., by the Foreign Scientific Publications Department of the National Center for Scientific, Technical and Economic Information Warsaw, 1976.

Kopecký, Z., Hlásková, L., and Orlowski, K. A. (2014). “An innovative approach to prediction energetic effects of wood cutting process with circular-saw blades," Wood Res. 59(5), 827-834.

Kopecký, Z., Hlásková, L., Solař, A., and Nesázal, P. (2019). “Cutting forces quasiorthogonal CNC milling," Wood Res. 64(5), 879-890.

Kramár, S., Trcala, M., Chitbanyong, K., Král, P., and Puangsin, B. (2020). "Basalt-fiberreinforced polyvinyl acetate resin: A coating for ductile plywood panels," Materials 13(1), 49.

Krauss, A., Piernik, M., and Pinkowski, G. (2016). "Cutting power during milling of thermally modified pine wood," Wood Ind./Drvna Industrija 67(3), 215-222.

Król, D. (2008). "Thermal destruction of hazardous waste - copper and lead emissions," Arch. of Waste Mana. and Envr. Prot. 7, 43-50. [in Polish]

Kržišnik, D., Lesar, B., Thaler, N., and Humar, M. (2018). "Influence of natural and artificial weathering on the colour change of different wood and wood-based materials," Forests 9(8), 488.

Kukla \& Warguła (2021). "Shredding of wood boards," BioResources 16(4), 8006-8021. 8018 
Kuvik, T., Krilek, J., Kovác, J., Štefánek, M., and Dvorak, J. (2017). "Impact of the selected factors on the cutting force when using a chainsaw," Wood Res. 62, 807-814.

Lin, L., Cao, J., Zhang, J., Cui, Q., and Liu, Y. (2020). "Enhanced anti-mold property and mechanism description of $\mathrm{Ag} / \mathrm{TiO}_{2}$ wood-based nanocomposites formation by ultrasound-and vacuum-impregnation," Nanomaterials 10(4), 682.

Macko, M., and Mrozinski, A. (2018). "Computer aided design of wood pellet machines," Int. Conf. on Com. Aided Eng., pp. 454-461, Springer, Cham.

Macko, M., and Mrozinski, A. (2019). "Work parameters research of wood pellet machine," AIP Conference Proceedings, 2077(1): 020038, AIP Publishing LLC.

Mandić, M. D., Porankiewicz, B., and Danon, G. J. (2015). "An attempt at modelling of cutting forces in oak peripheral milling," BioResources 10(3), 5489-5502.

Martínez-Conde, A., Krenke, T., Frybort, S., and Müller, U. (2017). "Comparative analysis of $\mathrm{CO}_{2}$ laser and conventional sawing for cutting of lumber and wood-based materials," Wood Sci. and Tech. 51(4), 943-966.

Mirski, R., Boruszewski, P., Trociński, A., and Dziurka, D. (2017). "The possibility to use long fibres from fast growing hemp (Cannabis sativa L.) for the production of boards for the building and furniture industry," BioResources 12(2), 3521-3529.

Mirski, R., Derkowski, A., Dziurka, D., Wieruszewski, M., and Dukarska, D. (2020). "Effects of chip type on the properties of chip-sawdust boards glued with polymeric diphenyl methane diisocyanate," Materials 13(6), 1329.

Narlığlu, N., Salan, T., Çetin, N. S., and Alma, M. H. (2018). "Evaluation of furniture industry wastes in polymer composite production," Mobilya ve Ahşap Malzeme Araştırmaları Dergisi 1(2), 78-85.

Nassef, M. G., El-Galy, I., and Hassanin, A. (2018). "Mechanical and dynamic characterization of sustainable composites based on food packaging waste," MATEC Web of Conferences, vol. 249, EDP Sciences, p. 01002.

Nemli, G., and Çolakoğlu, G. (2005). "The influence of lamination technique on the properties of particleboard," Building and Environment 40(1), 83-87.

Orlowski, K. A., and Ochrymiuk, T. (2017). "A newly-developed model for predicting cutting power during wood sawing with circular saw blades," Maderas. Ciencia y Tecnología 19(2), 149-162.

Orłowski, K. A., Ochrymiuk, T., Atkins, A., and Chuchala, D. (2013). "Application of fracture mechanics for energetic effects predictions while wood sawing," Wood Sci. and Tech. 47(5), 949-963.

Palka, D., and Tutak, M. (2018). "Economy of packaging and waste from packaging on the example of the wood industry," Int. Multidiscipl. Sci. GeoConf.: SGEM: Surveying Geology \& Mining Ecology Management 18, 49-56.

Porankiewicz, B., Axelsson, B., Grönlund, A. A., and Marklund, B. (2011). "Main and normal cutting forces by machining wood of Pinus sylvestris," BioResources 6(4), 3687-3713.

Pritchard, J., Ansell, M. P., Thompson, R. J. H., and Bonfield, P. W. (2001). "Effect of two relative humidity environments on the performance properties of MDF, OSB and chipboard," Wood Sci. and Tech. 35(5), 405-423.

Rydzkowski, T., and Michalska-Pożoga, I. (2016). "Analysis of intensity of changes in the moisture content of wood chips in the production of wood polymer composites during drying and storage processes," Wood Resources 61(3), 457-464. 
Rebollar, M., Pérez, R., and Vidal, R. (2007). "Comparison between oriented strand boards and other wood-based panels for the manufacture of furniture," Mat. \& Design 28(3), 882-888.

Reczulski, M. (2015). "Analysis of the construction and operation of system wood chipping and transfer chips," Wood Resources 60(4), 671-678.

Seo, H. J., Kim, S., Huh, W., Park, K. W., Lee, D. R., Son, D. W., and Kim, Y. S. (2016). "Enhancing the flame-retardant performance of wood-based materials using carbonbased materials," J. of Therm. Anal. and Calorim. 123(3), 1935-1942.

Stubdrup, K. R., Karlis, P., Roudier, S., and Delgado Sancho, L. (2016). "Best available techniques (BAT) reference document for the production of wood-based panels," JRC Science for Policy Report 2016, EUR 27732 EN.

publications.jrc.ec.europa.eu/repository/bitstream/JRC100269/wbp_bref_2016.pdf. Accessed 7 April 2021.

Swiss Krono Group (2021). (https://www.swisskrono.pl/en/mdm/ParticleBoards/Technical-data), accessed 13 August 2021.

Swiss Krono Group (2021). (https://www.swisskrono.pl/en/mdm/Melamine-FacedBoards/Technical-data), accessed 13 August 2021.

Swiss Krono Group (2021). (https://www.swisskrono.pl/en/mdb/OSB-boards/TechnicalData), accessed 13 August 2021.

Swiss Krono Group (2021). (https://www.swisskrono.pl/en/mdm/MDFBoards/Technical-Data), accessed 13 August 2021

Szpica, D. (2018). "Validation of indirect methods used in the operational assessment of LPG vapor phase pulse injectors," Measurement 118, 253-261.

Szpica, D., and Czaban, D. J. (2019). "Investigating of the combustion process in a diesel engine fueled with conventional and alternative fuels," $23^{\text {rd }}$ International Scientific Conference, Transport Means, Palanga, 2019.

Trochonowicz, M., and Galas, M. (2018). "Influence of air humidity and temperature on thermal conductivity of wood-based materials," Bud. i Archit. 17(4).

Walkowiak, M., Witczak, M., Sajdak, M., and Cichy, W. J. (2018). "Properties of solid biofuels obtained from residues of wood-based materials," Drewno: Prace Naukowe, Doniesienia, Komunikaty 61(202), 99-118.

Waluś, K. J., Warguła, Ł., Krawiec, P., and Adamiec, J. M. (2018). "Legal regulations of restrictions of air pollution made by non-road mobile machinery - The case study for Europe: A review," Envr. Sci. and Poll. Res. 25(4), 3243-3259.

Warguła, Ł., Krawiec, P., Waluś, K. J., and Kukla, M. (2020a). "Fuel consumption test results for a self-adaptive, maintenance-free wood chipper drive control system," Appl. Sci. 10(8), 2727.

Warguła, Ł., Kukla, M., Krawiec, P., and Wieczorek, B. (2020b). "Impact of number of operators and distance to branch piles on woodchipper operation," Forests 11(598), $1-14$.

Warguła, Ł., Walus, K. J., and Krawiec, P. (2019). "Working conditions of mobile wood chipping machines in the aspect of innovative drive control systems," Sylwan 163(09). [in Polish]

Wasielewski, R. (2019). "The use of engineered wood wastes for energy production," Arch. of Waste Mana. and Envr. Prot. 21(1).

Wasielewski, R., and Bałazińska, M. (2017). "Energy recovery from waste in the aspect of electricity and heat qualification as coming from renewable energy sources and participation the system of emissions trading," Ecological Eng. 18(5), 170-178.

Kukla \& Warguła (2021). "Shredding of wood boards," BioResources 16(4), 8006-8021. 8020 
Wei, W., Li, Y., Xue, T., Tao, S., Mei, C., Zhou, W., and Wang, T. (2018). "The research progress of machining mechanisms in milling wood-based materials," BioResources 13(1), 2139-2149.

Wojtkowiak, D., and Talaśka, K. (2019). "Determination of the effective geometrical features of the piercingpunch for polymer composite belts," The Int. J. of Adv. Manu. Tech. 104, 315-332.

Wojtkowiak, D., Talaśka, K., Malujda, I., and Domek, G. (2018). "Estimation of the perforation force for polymer composite conveyor belts taking into consideration the shape of the piercing punch," The Int. J. of Adv. Manu. Tech. 98, 2539-2561.

Yu, S. T., Yang, C. M., Ren, C. Q., and Luo, G. (2012). "Cutting force analysis of large branch crusher based on the finite element," Appl. Mech. and Mat. 152, 900-905.

Zhou, L., and Fu, Y. (2020). "Flame-retardant wood composites based on immobilizing with chitosan/sodium phytate/nano- $\mathrm{TiO}_{2}-\mathrm{ZnO}$ coatings via layer-by-layer selfassembly," Coatings 10(3), 296.

Article submitted: May 7, 2021; Peer review completed: August 10, 2021; Revised version received and accepted: August 16, 2021; Published: October 14, 2021.

DOI: $10.15376 /$ biores.16.4.8006-8021 